\title{
Comparative genomic and secretomic characterisation of endophytic Bacillus velezensis LC1 producing bioethanol from bamboo lignocellulose
}

\section{Hao Tang}

Leshan Normal University

Yuanqiu Li

Leshan Normal University

\section{Li Zheng}

Leshan Normal University

Lu Lei

Leshan Normal University

Xiaowen Yang

Leshan Normal University

Chaobing Luo ( 13366181512@163.com )

Leshan Normal University https://orcid.org/0000-0002-8460-9432

\section{Research}

Keywords: comparative genome, secretome, Bacillus velezensis LC1, bamboo lignocellulose, ethanol

Posted Date: December 3rd, 2019

DOI: https://doi.org/10.21203/rs.2.17974/v1

License: (c) (i) This work is licensed under a Creative Commons Attribution 4.0 International License.

Read Full License

Version of Record: A version of this preprint was published at Archives of Microbiology on April 1st, 2021. See the published version at https://doi.org/10.1007/s00203-021-02306-6. 


\section{Abstract}

Background: Compared to physical and chemical methods, microbial lignocellulosic degradation is a green process. Bacillus is an excellent organic matter degrader, and it has exhibited various abilities required for lignocellulose degradation, including the degradation of cellulose, hemicellulose and lignin. Several B. velezensis strains encode lignocellulosases. However, their usefulness based on their ability to transform biomass has not been appreciated. Genomic, comprehensive comparative genomic and secretomic analyses were used to clarify the lignocellulose-degrading potential of these bacteria, which is necessary for their future application.

Results: In the present study, the complete genomes of $20 \mathrm{~B}$. velezensis strains and an endophytic bacterium, $B$. velezensis $L C 1$, were analysed to find common and unique genes encoding carbohydrateactive enzymes (CAZymes) and evaluate their potentials to degrade lignocellulose. By comparative whole genomic and CAZyomic analyses of all 21 strains, we identified genes of lignocellulolytic enzymes with the potential to degrade cellulose $(\mathrm{GH} 5, \mathrm{GH} 30, \mathrm{GH} 4, \mathrm{GH} 1, \mathrm{GH} 16$ and $\mathrm{GH} 32)$ and hemicellulose $(\mathrm{GH} 43$, $\mathrm{GH} 30, \mathrm{GH} 51, \mathrm{GH} 26$ and GH53). Further identification of the secretome of $B$. velezensis LC1 by liquid chromatography-tandem mass spectrometry (LC-MS/MS) confirmed that a considerable number of proteins in the culture medium are involved in lignocellulose degradation, including endoglucanase, hemicellulases, and other related proteins. Moreover, assays of the activities of several lignocellulolytic enzymes including endoglucanase, exoglucanase, $\beta$-glucosidase, xylanase, lignin peroxidase, laccase, and manganese peroxidase show that these enzymes are more active in bamboo powder compared to glucose substrates. After a 6-day treatment, the degradation efficiencies of cellulose, hemicellulose and lignin from bamboo powder were $59.90 \%, 75.44 \%$ and $23.41 \%$, respectively. The hydrolysate was subjected to ethanol fermentation with Saccharomyces cerevisiae and Escherichia coli K011, yielding $10.44 \mathrm{~g} / \mathrm{L}$ ethanol after $96 \mathrm{~h}$.

Conclusions: These findings indicate that Bacillus velezensis strains have the potential to degrade a range of polysaccharides in lignocellulosic biomass. One strain, $B$. velezensis LC1, efficiently degrades bamboo lignocellulose components, allowing for subsequent ethanol production.

\section{Background}

Bamboo, a perennial woody grass with a high lignocellulose content, is considered an excellent raw material for the production of many valuable products, including ethanol and biogas [1-3]. Ethanol production is divided into the following processes: pretreatment of raw materials, saccharification of cellulose and hemicellulose, and fermentation of the hydrolysate. Lignocellulose degradation is a key link in the conversion of biomass into ethanol, and it remains a difficult problem to solve completely and effectively [4]. Much research has been devoted to the pretreatment of raw materials to improve saccharification efficiency [3,5]. Biological treatment, especially the microorganisms involved in degradation, has been mostly ignored in these research efforts, which have tended to concentrate on the unique mechanism and specific enzymes involved in lignocellulose degradation. Research on bacterial 
systems have tended to focus on strains with rapid growth, high adaptability, and those that are easy to genetically manipulate $[6,7]$.

Compared with physical and chemical methods, microbial lignocellulosic degradation is a green process[8]. Bacillus is generally an excellent degrader, with specific strains exhibiting various abilities for lignocellulose degradation, including the degradation of cellulose, hemicellulose, and lignin [9-13]. Several B. velezensis strains encode lignocellulosases [14-18]. They are often regarded as biological agents because of their capabilities in promoting growth and anti-pathogenic activity. However, their potential usefulness based on their ability to transform biomass has not been appreciated [19-24]. To prove their potential usefulness, genomic and comprehensive comparative genomic and secretomic analyses will be necessary to clarify their lignocellulose-degrading potential.

In the present study, the whole genome sequences of $21 \mathrm{~B}$. velezensis strains, including the endophytic bacteria, $B$. velezensis $L C 1$, were retrieved from the NCBI database to search for genes encoding carbohydrate-active enzymes (CAZymes). There are six categories of CAZymes; the GHs, PLs, CEs, and CBMs all play roles in the degradation of polysaccharides; AAs function in the depolymerisation of lignin and GTs $[25,26]$. Then, a comparative genomic analysis was conducted to reveal common and unique characteristics among these CAZyme genes. We analysed the secretomes of $B$. velezensis LC1 grown in a medium containing alkali-pretreated bamboo powder and explored the changes in the chemical components of pretreated bamboo lignocellulose. Furthermore, we measured lignocellulolytic enzyme activities and analysed the bamboo lignocellulose degradation by $B$. velezensis LC1. Finally, ethanol productivity of bamboo was assessed by a continuous reaction consisting of $B$. velezensis LC1 hydrolysing lignocellulose, Saccharomyces cerevisiae fermenting glucose, and Escherichia coli K011 fermenting xylose.

\section{Results And Discussion}

\section{Comparative genomic analysis of CAZymes of $B$. velezensis strains}

The assembled genome of $B$. velezensis LC1, which contains 44 GHs, 38 GTs, 30 CEs, 3 PLs, 6 AAs, and 15 CBMs, was compared to the genomes of other $B$. velezensis strains. The 20 B. velezensis strains consist of: $B$. velezensis 10075 , B. velezensis $157, B$. velezensis $\mathrm{FZB} 42, B$. velezensis $83, B$. velezensis UCMB5036, B. velezensis $\mathrm{LB002,} \mathrm{B.} \mathrm{velezensis} \mathrm{S3-1,} \mathrm{B.} \mathrm{velezensis} \mathrm{At1,} \mathrm{B.} \mathrm{velezensis} \mathrm{BCS}$ 1, B. velezensis JTYP2, B. velezensis BS-37, B. velezensis CN026, B. velezensis $\mathrm{B} 25, B$. velezensis $\mathrm{DR}-08$, $B$. velezensis LPL-K103, B. velezensis GFP-2, B. velezensis T20E-257, B. velezensis GYL4, B. velezensis TB1501, and $B$. velezensis $\mathrm{LS69}$. Their genomes were comparatively analysed with $B$. velezensis $\mathrm{LC1}$. At the whole genome level, the $B$. velezensis $\mathrm{LC1}$ resembles most $B$. velezensis DR-08 (Fig. 1), while at the CAZyome level, LC1 resembles most $B$. velezensis S3-1 (Fig. 2).

Genes encoding CAZymes were detected in 21 genomes (Table 1 and Table S1). Sequence analysis results reveal the common and unique features in these lignocellulose degradation genes (Table 1 and Table S1). For example, some cellulolytic enzyme genes such as GH30 and GH5 are common to 21 
strains, that also often contain endoglucanases (EC 3.2.1.4). GH1, GH4, and $\mathrm{GH} 16$ contribute to cellulose degradation by potentially functioning as 6-phospho- $\beta$-galactosidase, 6 -phospho- $\beta$-glucosidase, and $\beta-1,3-1,4-$ glucanase, respectively; they frequently appeared in 21 genomes. In addition, common genes capable of hemicellulose degradation were obtained. Arabinan endo-1,5- $\mathrm{a}-\mathrm{L}$-arabinosidase, $\mathrm{a}-\mathrm{N}$ arabinofuranosidase, and glucuronoxylanase are critical for xylan degradation; they belong to $\mathrm{GH} 43$, GH51, and GH30. GH53 hydrolyses ( $1 \rightarrow 4$ )- $\beta$-D-galactosidic linkages in type I arabinogalactans [27]. GH26 functions as $\beta$-mannosidase [28]. Some CEs with the potential to deacetylate $x y l a n s$ and xylooligosaccharides, for example, CE3 (acetyl xylan esterase) [29], and CE 7 (acetylxylan esterase) [30] were also found frequently. The coexistence of these genes suggests that they play important roles in the enzymatic degradation of cellulose and hemicellulose. We consider these degradation enzymes in $B$. velezensis to have potential use for biothanol production.

Two PL1 and one PL9 genes are found in 21 genomes and are known to play roles in pectin degradation. The action of pectatelyase on (1 $\rightarrow 4)$-a-D-galacturonan results in the production of oligosaccharides [31]. CE4, which contain polysaccharide deacetylases that function in polysaccharide degradation, [32] was also detected in the genomes. Moreover, we also identified several non-catalytic modules with binding functions, including CBM3, which binds to cellulose, and CBM6, which binds to amorphous cellulose and $\beta-1,4-x y l a n$ [33].

GH32 contains sucrose-6-phosphate hydrolase and levanase, and are thus expected to function in sucrose hydrolysis [34]. GH13 (a-amylase, a-glucosidase, a-glycosidase, and a-a-phosphorylase) and CBM50 (involved in starch hydrolysis) [35] were also detected. GH65 (maltose phosphorylase) was identified in several $B$. velezensis genomes; this sequence is associated with trehalose degradation [36].

There are few auxiliary activities (AA) genes in all strains. Only the AA10 family was annotated in all strains, while AA4, AA6, and AA7 were only found in strain LC1. AA4 includes vanillyl-alcohol oxidases that exert invertase activity on phenols [37]. In addition, AA7 can biotransform or detoxify lignocellulose [26]. Several Bacillus strains have been considered lignin degraders. For example, Bacillus sp. LD003 affects lignin fractions [38]; B. pumilus $\mathrm{C} 6$ and $B$. atrophaeus $\mathrm{B} 7$ have laccase activity that degrades kraft lignin and the dimer guaiacylglycerol-b-guaiacyl [10].

\section{Effect of alkali pretreatment on chemical components of bamboo}

Lignocellulose-derived ethanol is widely considered a clean liquid fuel [39]. However, raw lignocellulose has a recalcitrant structure that lowers bioconversion efficiency, making pretreatment necessary to make lignocellulose more vulnerable to enzymes or bacteria for the fermentation of ethanol and other products $[40,41]$. Bamboo lignocellulose pretreated by alkali has a higher enzymatic digestibility than the raw material [42-44]. In the present study, we used sodium hydroxide $(\mathrm{NaOH})$ to pretreat the bamboo powders. Table 2 lists the chemical compositions of pretreated and unpretreated bamboo powder (solid fraction) and shows that dried bamboo contains cellulose, hemicellulose, lignin, ash, neutral detergent fibre, acid detergent fibre, and acid detergent lignin in approximate percentages of $22.13 \pm 2.52,44.94 \pm 4.12,18.71$ $\pm 2.76,1.94 \pm 0.02,87.72 \pm 3.87,65.59 \pm 4.65$ and $20.65 \pm 1.77$, respectively. After alkaline pretreatment, 
the lignin content decreased to $6.92 \% \pm 0.84 \%$, while the hemicellulose increased to $30.19 \% \pm 2.61 \%$. Cellulose remained stable before and after alkaline pretreatment, which is consistent with previous studies [45]. The results indicate that $\mathrm{NaOH}$ pretreament of bamboo efficiently removes lignin without significantly impacting the cellulose.

\section{Identification of secretomes of $B$. velezensis LC1 grown on medium containing with bamboo powder}

To further confirm the lignocellulase system in B. velezensis LC1 cultured in bamboo powder, we analysed the secretomes of $B$. velezensis $\mathrm{LC} 1$ grown on bamboo powder and glucose medium (control). First, the supernatants of a three-day treatment were precipitated with $12 \%(\mathrm{w} / \mathrm{v})$ trichloroacetic aid (TCA) to obtain proteins. Secretomic protein was detected only in the bamboo powder medium (Fig. 3a). These proteins were analysed by 1D-PAGE (Fig. 3b) and LC-MS/MS. The basic characteristics of the proteins are shown in Fig. 3c. The pl values of most proteins are in the range of 5.0-10.0. A total of 142 proteins were identified; these include a lignocellulolytic enzyme, protease, and other proteins (Table S3). These proteins were then functionally annotated, resulting in the characterisation of $612,69,348$, and 79 proteins as being enriched in biological processes, cell components, molecular functions, and KEGG pathway functions, respectively (Fig. 3d; Fig. S1; Fig. S2). In addition, degradation-related enzymes including hemicellulases, cellulases, and other GHs were abundant in bamboo powder medium (Table 3).

Hemicellulose is the second most abundant component in lignocellulose; it is hydrolysed into monosaccharides by multiple enzyme systems [46-48]. Arabinogalactan endo-beta-1,4-galactanase (EC 3.2.1.89), which belongs to $\mathrm{GH} 53$, catalyses the hydrolysis of $\beta-1,4$-galactosidic bonds in arabinogalactan and galactan side chains [49]. Other GHs exhibit hemicellulose activities. For example, $\beta$ xylanases cleave the xylan backbone, while $\beta$-xylosidases release the xylose units from xylobiose and xylooligomers. Acetyl xylan esterase is an accessory enzyme that functions synergistically with other enzymes in removing side chain residues from the hemicellulose backbone $[50,51]$. In the present study, four hemicellulases were identified, consisting of one arabinogalactan endo- $\beta$-1,4-galactanase (GH53) (1384349889), one beta-xylanase (GH43) (1384351325), one glucuronoxylanase (GH30) (1384349284), and one acetylxylan esterase (CE1) (1384350660) (Table 3).

Cellulose is hydrolysed synergistically by different enzymes, that is, endoglucanases randomly break internal bonds, then, exoglucanases remove cellobiose, and finally $\beta$-glucosidases release glucose from cellobiose [52-55]. $\beta$-Glucanases catalyse the degradation of $\beta$-glucans and are classified into $\beta-1,3-1,4-$ glucanases (EC 3.2.1.73), $\beta$-1,4-glucanases (EC 3.2.1.4), $\beta$-1,3-glucanases (EC 3.2.1.39), and $\beta-1,3(4)$ glucanases (EC 3.2.1.6) [56-58]. Microbial $\beta-1,3-1,4-$ glucanases have been identified as $\mathrm{GH} 16$ and are mainly produced by Bacillus [59-62]. Two different enzymes, an endoglucanase (GH5) (1384349288) and a $\beta-1,3-1,4-$ glucanase (GH16) (1384351103), which probably participates in cellulose degradation, were identified (Table 3).

AAs play a vital role in lignin degradation [26]. In this study, two AA6s (1384350268 and 1384350569), one AA7 (1384350476), and one AA10 (1384349337) protein were identified. Moreover, other enzymes 
involved in starch degradation, plant cell wall modifications, and protein degradation (proteases) were detected (Table 3).

\section{Hydrolysis of bamboo powder by B. velezensis LC1 grown on medium with or without bamboo powder}

The following $B$. velezensis strains have attracted attention due to their applications in agriculture and biotechnology: $B$. velezensis GH1-13 [17], $B$. velezensis S3-1 [19], $B$. velezensis FZB42 [20], $B$. velezensis M75 [21], B. velezensis LS69 [18], B. velezensis 9912D [22], and B. velezensis S499 [23]. B. velezensis LC1, which has shown bamboo lignocellulose degrading ability, was isolated from the intestinal microbiome of Cyrtotrachelus buqueti. The lignocellulose degrading ability of $B$. velezensis LC1 was demonstrated through bamboo degrading experiments.

Enzymes play critical roles in lignocellulose degradation. For example, lignin peroxidase and manganese peroxidase are important and necessary for the degradation of lignin and laccase, respectively [63]. Endoglucanases, exoglucanases, and $\beta$-glucosidases synergistically act to degrade cellulose [64], while xylanases are essential components of the hemicellulose degrading system [65]. Then we measured cellulase (endoglucanase, $\beta$-glucosidase and exoglucanase), hemicellulase (xylanase), and ligninase (laccase, lignin peroxidase and manganese peroxidase) activities, the activities of xylanase, lignin peroxidase, and laccase were significantly higher for bamboo powder than those for glucose (Fig. 4). Endoglucanase, $\beta$-glucosidase, and manganese peroxidase activities for bamboo powder were significantly higher than those for glucose after $3 \mathrm{~d}$ of treatment. However, exoglucanase activity was higher after $4 \mathrm{~d}$ of treatment. These results indicate that higher lignocellulolytic enzyme activities are involved in bamboo lignocellulose degradation.

Then, we measured lignocellulose degradation efficiencies using pretreated bamboo powder. After $6 \mathrm{~d}$ of culturing, the degradation products were analysed. The degradation efficiencies of cellulose, hemicellulose, and lignin in bamboo powder were $59.90 \%, 75.44 \%$, and $23.41 \%$, respectively (Fig. $5 a$ ). Several $B$. velezensis strains have lignocellulose degrading ability [14-18], which supports our finding that B. velezensis LC1 can efficiently degrade bamboo lignocellulose components.

\section{Hydrolysate fermentation}

Bamboo used for mushroom cultivation contains abundant cellulose, which is considered suitable for bioethanol production. Much of the research devoted to bamboo lignocellulose bioethanol production have focused on the physical and chemical pretreaments [3,5]. In our study, the ethanol productivity of bamboo was assessed by a continuous reaction of $B$. velezensis LC1 hydrolysing lignocellulose, Saccharomyces cerevisiae fermenting glucose, and Escherichia coli K011 fermenting xylose. The bamboo-based ethanol production process is shown in Fig. 5b; its ethanol yield reached $10.44 \mathrm{~g} / \mathrm{L}$ at 96 $\mathrm{h}$, while the amount of reducing sugar decreased. This indicates that $B$. velezensis LC1 played an important role in the bioconversion of bamboo lignocellulose into ethanol.

\section{Conclusions}


The genomes of 21 strains of $B$. velezensis were compared and their CAZyomes were analysed. Genes with common and unique lignocellulolases were identified. The bamboo powder secretome of $B$. velezensis LC1 contains proteins related to lignocellulose degradation. The cellulose, hemicellulose, and lignin degradation of bamboo powder by strain LC1 were $59.90 \%, 75.44 \%$ and $23.41 \%$, respectively. The hydrolysate was subjected to ethanol fermentation, resulting in an ethanol yield of $10.44 \mathrm{~g} / \mathrm{L}$ at $96 \mathrm{~h}$. These findings indicate that $B$. velezensis $\mathrm{LC} 1$ efficiently degrades bamboo lignocellulose components that then yield ethanol.

\section{Methods}

\section{Mining of homologous genes related to lignocellulose degradation}

Genomic data of 21 B. velezensis strains were retrieved from the GenBank DNA database, including nucleotide, amino acid, and putative coding sequences (Suppl Table S2). These sequences were analysed by dbCAN (http://csbl.bmb.uga.edu/dbCAN/annotate.php) and dbCAN HMMs version 4.0 [66]. CAZymes were identified by the CAZy database [25], and homologous families were analysed by OrthMCL software http://orthomcl.org/orthomcl/and annotated manually.

\section{Phylogenetic analysis}

Whole genome phylogenomic analysis of LC1 was performed by aligning the whole genomes of LC1 and other retrieved representatives of $B$. velezensis. Mugsy was used to align the genomic data, and the bxpython tool kit (https://bitbucket.org/james_taylor/bx-python) was used to concatenate homologous blocks. RAxML version 7.2.8 (24) and FigTree version 1.3.1 (http://tree.bio.ed.ac.uk /software/fifigtree/) was used to construct and visualise phylogenetic trees from concatenated blocks using 1000 bootstrap replicates and the maximum-likelihood method. The CAZyome phylogenomic analysis was performed on homologous CAZy genes.

\section{Pretreament of the raw bamboo materials}

The bamboo materials were sampled from the bamboo botanical garden of the Bamboo Diseases and Pests Control and Resources Development Key Laboratory of Sichuan Province, China. The bamboo powders were prepared as described by Luo et al. [67]. BP samples were treated with $3 \%(w / w)$ Tween- 80 to enhance alkali pretreatment efficiency. Then, dried BPs were added in $1 \mathrm{M} \mathrm{NaOH}$ at a concentration of $10 \% \mathrm{w} / \mathrm{v}$, followed by autoclaving at $121^{\circ} \mathrm{C}$ for $60 \mathrm{~min}$. Afterwards, compounds were filtered and centrifuged $(10,000 \times \mathrm{g}$ for $10 \mathrm{~min})$. Precipitates were neutralised by $1 \mathrm{M} \mathrm{H}_{2} \mathrm{SO}_{4}$ and recentrifuged to remove salts formed during neutralisation. Finally, treated samples were washed by distilled water and dried to constant weight at $60^{\circ} \mathrm{C}$.

\section{Secretome preparation and analysis}


The $B$. velezensis LC1 was cultured in liquid medium at $\mathrm{pH} 7.2,37^{\circ} \mathrm{C}$ and $200 \mathrm{rpm}$. The medium consists of pretreated bamboo shoot powder $(10 \mathrm{~g} / \mathrm{L}),(\mathrm{NH} 4)_{2} \mathrm{SO}_{4}(2 \mathrm{~g} / \mathrm{L}), \mathrm{K}_{2} \mathrm{HPO}_{4}(1 \mathrm{~g} / \mathrm{L}), \mathrm{KH}_{2} \mathrm{PO}_{4}(1 \mathrm{~g} / \mathrm{L}), \mathrm{MgSO}_{4}$ $(0.2 \mathrm{~g} / \mathrm{L}), \mathrm{CaCl}_{2}(0.1 \mathrm{~g} / \mathrm{L}), \mathrm{FeSO}_{4} \cdot 7 \mathrm{H}_{2} \mathrm{O}(0.05 \mathrm{~g} / \mathrm{L})$, and $\mathrm{MnSO}_{4} \cdot \mathrm{H}_{2} \mathrm{O}(0.02 \mathrm{~g} / \mathrm{L})$. Cultures of B. velezensis LC1 growing in bamboo powder media were harvested on the 3rd day. First, the culture was filtered, then the supernatant was obtained by centrifugation (5000 rpm, $10 \mathrm{~min}, 4{ }^{\circ} \mathrm{C}$ ), followed by another round of filtration (0.2 $\mu \mathrm{m}$ membranes). The filtrate was precipitated by acetone to obtain total proteins [68]. Secretome proteins were harvested by precipitating the filtrate using $12 \%(\mathrm{w} / \mathrm{v})$ trichloroacetic acid overnight at $4{ }^{\circ} \mathrm{C}$, then centrifuging $\left(12,000 \mathrm{rpm}, 30 \mathrm{~min}, 4^{\circ} \mathrm{C}\right)$, and finally washing for three times with $96 \%$ ethanol $(\mathrm{v} / \mathrm{v})$. The dried secretome protein pellets were resuspended in a solution containing $8 \mathrm{M}$ urea and 4\% (w/v) 3-[(3-cholamidopropyl) dithiothreitol.

LC-MS/MS analysis was implemented at Shanghai OE Biotech. Co., Ltd. as previously described [69]. Measurements were performed by nanoflow reversed-phase C18 liquid chromatography (EASY nLC, Thermo Scientific) coupled online to a 7-Tesla linear ion trap Fourier-Transform ion cyclotron resonance mass spectrometer (LTQ FT Ultra, Thermo Scientific). MaxQuant software was used to identify and quantify proteomic spectra, and then map the peptides to the annotated B. velezensis LC1 genome (data not shown) using the default settings [70].

\section{Pretreated bamboo powder degradation by $B$. velezensis LC1}

To obtain fermentable sugar from bamboo, $B$. velezensis LC1 was used to degrade the bamboo powder. The $B$. velezensis LC1 was cultured as described above for $6 \mathrm{~d}$. Growth was terminated by heating at 100 ${ }^{\circ} \mathrm{C}$ for $30 \mathrm{~min}$. After centrifuging (13,000 rpm, $\left.10 \mathrm{~min}\right)$, the supernatant hydrolysate and pellet were collected. The pellet was dried and weighed to determine the levels of cellulose using the Van Soest method [71]. The glucose and xylose contents of the superficial hydrolysate were measured according to the NREL methods [72]. The bamboo shoot supernatant hydrolysate was sterilised and stored at $-20{ }^{\circ} \mathrm{C}$ until it was used for ethanol fermentation.

\section{Enzyme assays}

Two millilitres of supernatant hydrolysate were obtained daily from 6-d-cultures for assays performed to measure lignocellulolase activities as described by Luo et al. [73]. Briefly, carboxymethyl cellulose (CMC), microcrystalline cellulose (MCC), and salicin were used as substrates to measure the activities of endoglucanase, exoglucanase, and $\beta$-glucosidase, respectively. Veratryl alcohol (VA), 2,2'-azino-bis (ABTS), and xylan were used as substrates to determine LiP, laccase, and xylanase activities, respectively. Manganese peroxidase ( $\mathrm{MnP})$ activity was measured spectrophotometrically by monitoring the oxidation of 2,6-DMP at $469 \mathrm{~nm}\left(\varepsilon 469=49,600 \mathrm{~mol}^{-1} \mathrm{~cm}^{-1}\right)$. All the experiments were repeated five times.

\section{Fermentation}

The glucose-fermenting Saccharomyces cerevisiae was pre-cultured in YPD at $30{ }^{\circ} \mathrm{C}$ for $24 \mathrm{~h}$, while Escherichia coli K011, a xylose-fermenting strain, was pre-cultured in LB at $37^{\circ} \mathrm{C}$ for 24 h. S. cerevisiae 
$(50 \mathrm{~g} / \mathrm{L})$ and E. coli K011 (100 g/L) cells were prepared after centrifugation of the pre-cultured cells. The initial cell concentrations were $0.33 \mathrm{~g} / \mathrm{L}$ (S. cerevisiae) and $1.0 \mathrm{~g} / \mathrm{L}$ (E. coli KO11) at the beginning of fermentation. One-hundred millilitres of hydrolysate was used for ethanol fermentation in 250-ml serum bottles under anaerobic conditions at $37^{\circ} \mathrm{C}$. The fermentation system was shaken at $200 \mathrm{rpm}$ for $96 \mathrm{~h}$. Starting from $48 \mathrm{~h}$ of fermentation, ethanol production was monitored every $12 \mathrm{~h}$. The ethanol concentration was determined via High Performance Liquid Chromatography (HPLC). All reactions were repeated three times.

\section{List Of Abbreviations}

B. velezensis: Bacillus velezensis, GH: Glycoside Hydrolase; GT: glycosyltransferase; CE: carbohydrate esterase; CBM: carbohydrate binding domain; PL: polysaccharide lyase; AA: Auxiliary Activitie; CAZyme: carbohydrate-active enzyme; NCBl: the national center for biotechnology information; ABTS: [2,2'-Azinobis (3-ethylbenzothiazoline-6- sulfonic acid)]; BP: bamboo powder; YPD: Yeast Extract Peptone Dextrose Medium; DNS: 3,5-dinitrosalicylic acid; CDS: Sequence coding for amino acids in protein; NCBI: National Centre for Biotechnology Information.

\section{Declarations}

\section{Ethical approval and consent to participate}

Not applicable.

\section{Consent for publication}

The authors have consented for publication.

\section{Availability of data and material}

The sequence reads from this article have been deposited at the NCBI Sequence Read Archive under the accession PRJNA574012. The assembly data set supporting the results of this article has been deposited at GenBank under the accession CP044349. The version described in this paper is CP044349.

\section{Competing interests}

The authors declare that they have no competing interests.

\section{Funding}

This work was supported by Sichuan science and technology program (2019YFG0139) and Scientific Research Foundation of Leshan Normal University (XJR19001).

\section{Authors' contributions}


CBL designed and performed the experiments; $H T$ and YQL wrote the manuscript; LZ, LL, YQL, XWY and $\mathrm{HT}$ analyzed the data. All authors read and approved the final manuscript.

\section{Acknowledgements}

The data were analyzed on the free online platform of Majorbio Cloud Platform (www.majorbio.com).

\section{Authors' information}

${ }^{1}$ College of life science, Leshan Normal University, Leshan, 614000, Sichuan, China.

\section{References}

1. Yuan Z, Wen Y, Kapu NS, Beatson R, Mark Martinez D. A biorefinery scheme to fractionate bamboo into high-grade dissolving pulp and ethanol. Biotechnol Biofuels. 2017;10:38.

2. Yuan Z, Wen Y. Evaluation of an integrated process to fully utilize bamboo biomass during the production of bioethanol. Bioresour Technol. 2017;236:202-211.

3. Wi SG, Lee DS, Nguyen QA, Bae HJ. Evaluation of biomass quality in short-rotation bamboo (Phyllostachys pubescens) for bioenergy products. Biotechnol Biofuels. 2017;10:127.

4. Mansour AA, Da CA, Arnaud T, Lu-Chau TA, Fdz-Polanco M, Moreira MT, et al. Review of lignocellulolytic enzyme activity analyses and scale-down to microplate-based assays. Talanta. 2016;150:629-637.

5. Chen TY, Wen JL, Wang B, Wang HM, Liu CF, Sun RC. Assessment of integrated process based on autohydrolysis and robust delignification process for enzymatic saccharification of bamboo. Bioresour Technol. 2017;244:717-725.

6. Woo HL, Hazen TC, Simmons BA, DeAngelis KM. Enzyme activities of aerobic lignocellulolytic bacteria isolated from wet tropical forest soils. Syst Appl Microbiol. 2014;37(1):60-7.

7. Dam P, Kataeva I, Yang SJ, Zhou F, Yin Y, Chou W, et al. Insights into plant biomass conversion from the genome of the anaerobic thermophilic bacterium Caldicellulosiruptor bescii DSM 6725. Nucleic Acids Res. 2011;39(8):3240-54.

8. Capolupo L, Faraco V. Green methods of lignocellulose pretreatment for biorefnery development. Appl Microbiol Biotechnol. 2016;100(22):9451-9467.

9. Bandounas L, Wierckx NJ, de Winde JH, Ruijssenaars HJ. Isolation and characterization of novel bacterial strains exhibiting ligninolytic potential. BMC Biotechnol. 2011;11(1):94.

10. Huang XF, Santhanam N, Badri DV, Hunter WJ, Manter DK, Decker SR, et al. Isolation and characterization of lignin-degrading bacteria from rainforest soils. Biotechnol Bioeng. 2013;110(6):1616-1626.

11. Zhu D, Tanabe SH, Xie C, Honda D, Sun J, Ai L. Bacillus ligniniphilus nov., an alkaliphilic and halotolerant bacterium isolated from sediments of the South China Sea. Int J Syst Evol Microbiol. 2014;64(Pt 5):1712-1717. 
12. Khelil O, Choubane S, Cheba BA. Polyphenols content of spent coffee grounds subjected to physicochemical pretreatments influences lignocellulolytic enzymes production by Bacillus R2. Bioresour Technol. 2016;211:769-773.

13. Gong G, Lee SM, Woo HM, Park TH, Um Y. Influences of media compositions on characteristics of isolated bacteria exhibiting lignocellulolytic activities from various environmental sites. Appl Biochem Biotechnol. 2017;183(3):931-942.

14. Niazi A, Manzoor S, Asari S, Bejai S, Meijer J, Bongcam-Rudloff E. Genome analysis of Bacillus amyloliquefaciens plantarum UCMB5113: a rhizobacterium that improves plant growth and stress management. PLoS One. 2014;9(8):e104651.

15. Chen XH, Koumoutsi A, Scholz R, Schneider K, Vater J, Sussmuth R, et al. Genome analysis of Bacillus amyloliquefaciens FZB42 reveals its potential for biocontrol of plant pathogens. $J$ Biotechnol. 2009;140(1-2):27-37.

16. He P, Hao K, Blom J, Ruckert C, Vater J, Mao Z, et al. Genome sequence of the plant growth promoting strain Bacillus amyloliquefaciens plantarum B9601-Y2 and expression of mersacidin and other secondary metabolites. J Biotechnol. 2012;164(2):281-291.

17. Kim SY, Song H, Sang MK, Weon HY, Song J. The complete genome sequence of Bacillus velezensis strain $\mathrm{GH} 1-13$ reveals agriculturally benefcial properties and a unique plasmid. J Biotechnol. 2017;259:221-227.

18. Liu G, Kong Y, Fan Y, Geng C, Peng D, Sun M. Whole-genome sequencing of Bacillus velezensis LS69, a strain with a broad inhibitory spectrum against pathogenic bacteria. J Biotechnol. 2017;249:2024.

19. Jin Q, Jiang Q, Zhao L, Su C, Li S, Si F, et al. Complete genome sequence of Bacillus velezensis S3-1, a potential biological pesticide with plant pathogen inhibiting and plant promoting capabilities. $J$ Biotechnol. 2017;259:199-203.

20. Chen L. Complete genome sequence of Bacillus velezensis LM2303, a biocontrol strain isolated from the dung of wild yak inhabited Qinghai-Tibet plateau. J Biotechnol. 2017;251:124-127.

21. Kim SY, Lee SY, Weon HY, Sang MK, Song J . Complete genome sequence of Bacillus velezensis M75, a biocontrol agent against fungal plant pathogens, isolated from cotton waste. J Biotechnol. 2017;241:112-115.

22. Pan HQ, Li QL, Hu JC. The complete genome sequence of Bacillus velezensis 9912D reveals its biocontrol mechanism as a novel commercial biological fungicide agent. J Biotechnol. 2017;247:25-28.

23. Molinatto G, Puopolo G, Sonego P, Moretto M, Engelen K, Viti C, et al. Complete genome sequence of Bacillus amyloliquefaciens plantarum S499, a rhizobacterium that triggers plant defences and inhibits fungal phytopathogens. J Biotechnol. 2016;238:56-59.

24. Belbahri L, Chenari Bouket A, Rekik I, Alenezi FN, Vallat A, Luptakova L, et al. Comparative genomics of Bacillus amyloliquefaciens strains reveals a core genome with traits for habitat adaptation and a secondary metabolites rich accessory genome. Front Microbiol. 2017;8(8):1438. 
25. Lombard V, Ramulu HG, Drula E, Coutinho PM, Henrissat B. The carbohydrate-active enzymes database (CAZy) in 2013. Nucleic Acids Res. 2014;42:D490.

26. Levasseur A, Drula E, Lombard V, Coutinho PM, Henrissat B. Expansion of the enzymatic repertoire of the CAZy database to integrate auxiliary redox enzymes. Biotechnol Biofuels. 2013;6:41.

27. Vanholme B, Jacob J, Cannoot B, Gheysen G, Haegeman A. Arabinogalactan endo-1,4- $\beta-$ galactosidase: a putative plant cell wall-degrading enzyme of plant-parasitic nematodes. Nematology. 2009;11(5):739-747.

28. Onilude AA, Fadahunsi IF, Antia UE, Garuba EO, Inuwa M. Characterization of crude alkaline $\beta$ mannosidase produced by Bacillus $3 \mathrm{~A}$ isolated from degraded palm kernel cake. J Inorg Biochem. 2013;81(1-2):23-27.

29. Zhang J, Siika-Aho M, Tenkanen M, Viikari L. The role of acetyl xylan esterase in the solubilization of xylan and enzymatic hydrolysis of wheat straw and giant reed. Biotechnol Biofuels. 2011;4(1):60.

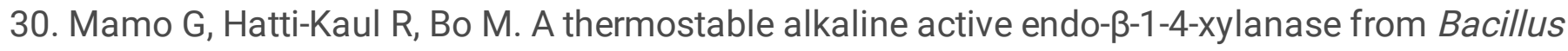
halodurans S7: Purifcation and characterization. Enzyme Microbial Technol. 2006;39(7):1492-1498.

31. See-Too WS, Chua KO, Lim YL, Chen JW, Convey P, Mohd Mohidin TB, et al. Complete genome sequence of Planococcus donghaensis JH1(T), a pectin-degrading bacterium. J Biotechnol. 2017;252:11-14.

32. Biely P. Microbial carbohydrate esterases deacetylating plant polysaccharides. Biotechnol Adv. 2012;30(6):1575-1588.

33. Sun C, Fu GY, Zhang CY, Hu J, Xu L, Wang RJ, et al. Isolation and complete genome sequence of Algibacter alginolytica nov., a novel seaweed-degrading bacteroidetes bacterium with diverse putative polysaccharide utilization loci. Appl Environ Microbiol. 2016;82(10):2975-2987.

34. Bezzate S, Steinmetz M, Aymerich S. Cloning, sequencing, and disruption of a levanase gene of Bacillus polymyxa J Bacteriol. 1994;176(8):2177-2183.

35. Graebin NG, Schoffer Jda N, Andrades D, Hertz PF, Ayub MA, Rodrigues RC. Immobilization of glycoside hydrolase families $\mathrm{GH} 1, \mathrm{GH} 13$, and $\mathrm{GH} 70$ : state of the art and perspectives. Molecules. 2016;21(8):1074.

36. Inoue Y, Yasutake N, Oshima Y, Yamamoto Y, Tomita T, Miyoshi S, et al. Cloning of the maltose phosphorylase gene from Bacillus strain RK-1 and Efcient Production of the cloned gene and the trehalose phosphorylase gene from Bacillus stearothermophilus SK-1 in Bacillus subtilis. Biosci Biotechnol Biochem. 2002;66(12):2594-2599.

37. Heuvel RHHVD, Fraaije MW, Mattevi A, Berkel WJHV. Structure, function and redesign of vanillylalcohol oxidase. In: International Congress Series. 2002.

38. Luaine B, Wierckx NJ, Winnde JH, Ruijssenaars HJ. Isolation and characterization of novel bacterial strains exhibiting ligninolytic potential. BMC Biotechnol. 2011;11(1):94.

39. Zaldivar J, Nielsen J, Olsson L. Fuel ethanol production from lignocellulose: a challenge for metabolic engineering and process integration. Appl Microbiol Biotechnol. 2011;56:17-34. 
40. Zhao L, Cao GL, Wang AJ, Ren HY, Dong D, Liu ZN, et al. Fungal pretreatment of cornstalk with Phanerochaete chrysosporium for enhancing enzymatic saccharification and hydrogen production. Bioresour Technol. 2012;114:365-369.

41. Kurakake M, Ide N, Komaki T. Biological pretreatment with two bacterial strains for enzymatic hydrolysis of office paper. Curr Microbiol. 2007;54:424-428.

42. Yamashita Y, Shono M, Sasaki C, Nakamura Y. Alkaline peroxide pretreatment for efficient enzymatic saccharification of bamboo. Carbohydrate Poly. 2010;79:914-920.

43. Yuan Z, Kapu NS, Beatson R, Chang XF, Martinez DM. Effect of alkaline pre-extraction of hemicelluloses and silica on kraft pulping of bamboo (Neosinocalamus affinis Keng). Ind Crops Prod. 2016;91:66-75.

44. Song $X$, Jiang Y, Rong X, Wei W, Wang S, Nie S. Surface characterization and chemical analysis of bamboo substrates pretreated by alkali hydrogen peroxide. Bioresour Technol. 2016;216:1098-1101.

45. Vena PF, Brienzo M, del Prado García-Aparicio M, Görgens JF, Rypstra T. Hemicelluloses extraction from giant bamboo (Bambara balcooa Roxburgh) prior to kraft or soda-AQ pulping and its effect on pulp physical properties. Holzforschung. 2013;67:863-870.

46. Adav SS, Li AA, Manavalan A, Punt P, Sze SK. Quantitative iTRAQ secretome analysis of Aspergillus niger reveals novel hydrolytic enzymes. J Proteome Res. 2010;9(8):3932-3940.

47. Biely P. Microbial xylanolytic systems. Trends Biotechnol. 1985;3(11):286-290.

48. Coughlan MP, Hazlewood GP. Beta-1,4-D-xylan-degrading enzyme systems: biochemistry, molecular biology and applications. Biotechnol Appl Biochem. 1993;17(Pt 3):259-289.

49. Torpenholt S, Le Nours J, Christensen U, Jahn M, Withers S, Ostergaard PR, et al. Activity of three B-1,4-galactanases on small chromogenic substrates. Carbohydr Res. 2011;346:2028-33.

50. Zhang JH, Siika-Aho M, Tenkanen M, Viikari L. The role of acetyl xylan esterase in the solubilization of xylan and enzymatic hydrolysis of wheat straw and giant reed. Biotechnol Biofuels. 2011;4:60.

51. Yang WX, Bai YG, Yang PL, Luo HY, Huang HQ, Meng K, et al. A novel bifunctional GH51 exo-a-Iarabinofuranosidase/endo-xylanase from Alicyclobacillus A4 with significant biomass-degrading capacity. Biotechnol Biofuels. 2015;8:197.

52. Goyal A, Ghosh B, Eveleigh D. Characteristics of fungal cellulases. Bioresour Technol. $1991 ; 36(1): 37-50$.

53. Rabinovich ML, Bolobova AV, Vasil'chenko LG. Fungal decomposition of natural aromatic structures and xenobiotics: A Review. Appl Biochem Microbiol. 2004;40(1):1-17.

54. Rabinovich ML, Melnick MS, Bolobova AV. The structure and mechanism of action of cellulolytic enzymes. Biochem Mosc. 2002;67(8):850-871.

55. Lynd LR, Cushman JH, Nichols RJ, Wyman CE: Fuel ethanol from cellulosic biomass. Science. 1991;251(4999):1318-1323.

56. McCarthy T, Hanniffy O, Savage A, Tuohy MG. Catalytic properties and mode of action of three endo$\beta$-glucanases from Talaromyces emersonii on soluble $\beta-1,4$-and $\beta-1,3,1$, 4-linked glucans. Int J Biol 
Macromol. 2003;33:141-148.

57. Boyce A, Walsh G. Production, purification and application relevant characterization of an endo-1, 3(4)-ß-glucanase from Rhizomucor miehei. Appl Microbiol Biotechnol. 2007;76:835-841.

58. Yang S, Yan Q, Jiang Z, Fan G, Wang L. Biochemical characterization of a novel thermostable $\beta$-1, 31, 4-glucanase (lichenase) from Paecilomyces thermophila. J Agric Food Chem. 2008;56:53455351.

59. Ekinci MS, McCrae SI, Flint HJ. Isolation and overexpression of a gene encoding an extracellular $\beta$-(1, 3-1, 4)-glucanase from Streptococcus bovis Appl Environ Microbiol. 1997;63:3752-3756.

60. Planas A. Bacterial 1, 3-1, 4- $\beta$-glucanases: structure, function and protein engineering. Biochem Biophys Acta. 2000;1543:361-382.

61. Teng D, Wang J, Fan Y, Yang Y, Tian Z, Luo J, et al. Cloning of $\beta$-1, 3-1, 4-glucanase gene from Bacillus licheniformis EGW039 (CGMCC 0635) and its expression in Escherichia coli BL21 (DE3). Appl Microbiol Biotechnol. 2006;72:705-712.

62. Huang HQ, Yang PL, Luo HY, Tang HG, Shao N, Yuan TZ, et al. High-level expression of a truncated 1, 3-1, 4- $\beta$-D-glucanase from Fibrobacter succinogenes in Pichia pastoris by optimization of codons and fermentation. Appl Microbiol Biotechnol. 2008;78:95-103.

63. Geib SM, Filley TR, Hatcher PG, Hoover K, Carlson JE, Jimenez-Gasco MDM, et al. Lignin degradation in wood-feeding insects. Proc Natl Acad Sci USA. 2008;105:12932.

64. Clark AJ. Biodegradation of cellulose: enzymology and biotechnology. Colourage. 1996;5:841.

65. Sun J, Tian C, Diamond S, Glass NL. Deciphering transcriptional regulatory mechanisms associated with hemicellulose degradation in Neurospora crassa. Eukaryot Cell. 2012;11:482-93.

66. Yin Y, Mao X, Yang J, Chen X, Mao F, Xu Y. dbCAN: a WEB resource for automated carbohydrateactive enzyme annotation. Nucleic Acids Res. 2012;40:445-51.

67. Luo C, Li Y, Chen Y, Fu C, Nong X, Yang Y. Degradation of bamboo lignocellulose by bamboo snout beetle Cyrtotrachelus buqueti in vivo and vitro: efficiency and mechanism. Biotechnol Biofuels. 2019;12:75.

68. Tiwari R, Singh S, Nain PK, Rana S, Sharma A, Pranaw K, et al. Harnessing the hydrolytic potential of phytopathogenic fungus Phoma exigua ITCC 2049 for saccharifcation of lignocellulosic biomass. Bioresour Technol. 2013;150:228-34.

69. Baldrian P, Valaskova V. Degradation of cellulose by basidiomycetous fungi. FEMS Microbiol Rev. 2008;32(3):501-21.

70. Ghose TK. Measurement of cellulase activities. Pure Appl Chem. 1987;59(2):257-68.

71. Van Soest PJ, Robertson JB, Lewis BA. Methods for dietary fiber, neutral detergent fiber, and nonstarch polysaccharides in relation to animal nutrition. J Dairy Sci. 1991;74:3583-97.

72. Sluiter A, Hames B, Ruiz R, Scarlata C, Sluiter J, Templeton D, et al. Determination of structural carbohydrates and lignin in biomass. Version 2012. National Renewable Energy Laboratory, USA. 2012. 
73. Luo CB, Li YQ, Liao H, Yang YJ. De novo transcriptome assembly of the bamboo snout beetle Cyrtotrachelus buqueti reveals ability to degrade lignocellulose of bamboo feedstock. Biotechnol Biofuels. 2018;11:292.

\section{Tables}

Table 1. Annotated common genes encoding lignocellulose-degrading enzymes of $21 B$. velezensis strains

\begin{tabular}{|c|c|c|c|}
\hline Classification & CAZy & Predicted function & EC number \\
\hline \multirow[t]{15}{*}{ Cellulose-related } & GH5 & endo-1,4- $\beta$-glucanase & EC 3.2.1.4 \\
\hline & GH30 & glucan endo-1,6- $\beta$-glucosidase & EC 3.2.1.- \\
\hline & GH4 & 6-phospho- $\beta$-glucosidase & EC 3.2.1.86 \\
\hline & $\mathrm{CH} 4$ & 6-phospho- $\alpha$-glucosidase & EC 3.2.1- \\
\hline & GH4 & alpha-glucosidase/alpha-galactosidase & EC:3.2.1.20 \\
\hline & GH4 & 6-phospho- $\beta$-glucosidase & EC 3.2.1.86 \\
\hline & GH1 & 6-phospho-beta-galactosidase & EC:3.2.1.85 \\
\hline & GH1 & aryl-phospho-beta-D-glucosidase & EC:3.2.1.86 \\
\hline & GH1 & 6-phospho- $\beta$-galactosidase & EC 3.2.1.85 \\
\hline & GH16 & $\beta$-glucanase & EC 3.2.1.- \\
\hline & GH32 & sucrose-6-phosphate hydrolase & EC 2.4.1.- \\
\hline & GH32 & levanase & EC 3.2.1.65 \\
\hline & GH13 & $\alpha$-glucosidase & EC 3.2.1.20 \\
\hline & PL1 & pectate lyase & EC 4.2.2.- \\
\hline & PL9 & pectate lyase & EC 4.2.2.2 \\
\hline \multirow[t]{8}{*}{ Hemicellulose-related } & GH43 & arabinan endo-1,5- $\alpha$-L-arabinosidase & EC 3.2.1.- \\
\hline & GH43 & arabinoxylan arabinofuranohydrolase & EC 3.2.1.- \\
\hline & GH43 & 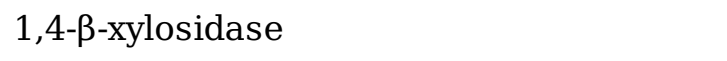 & EC 3.2.1.37 \\
\hline & GH51 & $\alpha-\mathrm{N}$-arabinofuranosidase & EC 3.2.1.55 \\
\hline & GH30 & glucuronoxylanase & EC 3.2.1.- \\
\hline & CE 7 & acetylxylan esterase & EC 3.1.1.72 \\
\hline & CE 3 & acetylxylan esterase & EC 3.1.1.72 \\
\hline & GH53 & arabinogalactan endo-1,4- $\beta$-galactosidase & EC 3.2.1.89 \\
\hline
\end{tabular}

Table 2. Chemical components of bamboo powder (BP) in raw and alkali-pretreated materials 


\begin{tabular}{lcc}
\hline Components & Raw material & Alkali pretreament \\
\hline NDF(\%) & $87.72 \pm 3.87$ & $90.11 \pm 3.18$ \\
ADF(\%) & $65.59 \pm 4.65$ & $59.92 \pm 5.97$ \\
ADL(\%) & $20.65 \pm 1.77$ & $16.58 \pm 2.51$ \\
ASH(\%) & $1.94 \pm 0.02$ & $9.66 \pm 0.53$ \\
Hemicellulose(\%) & $22.13 \pm 2.52$ & $30.19 \pm 2.61$ \\
Cellulose(\%) & $44.94 \pm 4.12$ & $43.34 \pm 2.72$ \\
Lignin(\%) & $18.71 \pm 2.76$ & $6.92 \pm 0.84$ \\
\hline
\end{tabular}

Table 3. Identification of the main CAZy proteins in the secretome of B. velezensis LC1 in bamboo powder (BP) culture 


\begin{tabular}{|c|c|c|c|c|c|c|}
\hline Locus tag & Description & Peptides & $\begin{array}{l}\text { Unique } \\
\text { Peptides }\end{array}$ & $\begin{array}{l}\text { Protein } \\
\text { mass } \\
(\mathrm{kDa})\end{array}$ & $\begin{array}{l}\text { Isoelectric } \\
\text { point }\end{array}$ & Score \\
\hline 1384350573 & $\begin{array}{l}\text { Bifunctional penicillin-binding } \\
\text { protein 1C }\end{array}$ & 2 & 2 & 88.3 & 9.88 & 3.92 \\
\hline 1384350643 & $\begin{array}{l}\text { Putative multimodular } \\
\text { carbohydrate-active enzyme }\end{array}$ & 3 & 3 & 92.9 & 6.65 & 8.73 \\
\hline 1384351304 & ATP synthase subunit alpha & 4 & 4 & 56 & 5.15 & 12.9 \\
\hline 1384351201 & Glycosyltransferase 2 & 3 & 3 & 55 & 6.58 & 4.67 \\
\hline 1384349288 & Endoglucanase & 3 & 3 & 55.2 & 8.1 & 2.87 \\
\hline 1384349889 & $\begin{array}{l}\text { Arabinogalactan endo-beta-1,4- } \\
\text { galactanase }\end{array}$ & 8 & 8 & 41.3 & 8.56 & 12.32 \\
\hline 1384351325 & Beta-xylanase & 5 & 5 & 42.2 & 6.98 & 11.07 \\
\hline 1384347997 & Sucrose-6-phosphate hydrolase & 10 & 10 & 56.1 & 5.69 & 54.68 \\
\hline 1384351193 & Sucrose-6-phosphate hydrolase & 4 & 4 & 66.2 & 7.46 & 2.18 \\
\hline 1384349284 & Glucuronoxylanase & 10 & 10 & 47.8 & 8.29 & 28.43 \\
\hline 1384351103 & Endo-beta-1,3-1,4-glucanase & 5 & 5 & 26.7 & 6.92 & 15.06 \\
\hline 1384348333 & Alpha-glycosidase & 12 & 12 & 119 & 4.88 & 38.21 \\
\hline 1384347992 & Alpha-amylase & 7 & 7 & 72.4 & 6.49 & 29.61 \\
\hline 1384351150 & 6-phospho-beta-glucosidase & 5 & 5 & 48.6 & 5.4 & 4.16 \\
\hline 1384350269 & Beta-amylase & 2 & 2 & 55.1 & 5.48 & 2.73 \\
\hline 1384348933 & Serine aminopeptidase & 9 & 9 & 8.4 & 4.96 & 2.75 \\
\hline 1384350660 & Acetylxylan esterase & 2 & 2 & 35.5 & 6.11 & 4.83 \\
\hline 1384351298 & $\begin{array}{l}\text { Serine } \\
\text { hydroxymethyltransferase }\end{array}$ & 2 & 2 & 45 & 6.21 & 5.5 \\
\hline 1384350476 & FAD-binding oxidoreductase & 2 & 2 & 50.1 & 9 & 4.16 \\
\hline 1384350268 & $\begin{array}{l}\text { NAD }(P) H \text {-dependent } \\
\text { oxidoreductase }\end{array}$ & 4 & 4 & 25.6 & 5.97 & 9.25 \\
\hline 1384350569 & $\begin{array}{l}\text { NAD }(P) \text {-dependent } \\
\text { oxidoreductase }\end{array}$ & 2 & 2 & 31.2 & 5.05 & 3.01 \\
\hline
\end{tabular}

\section{Figures}




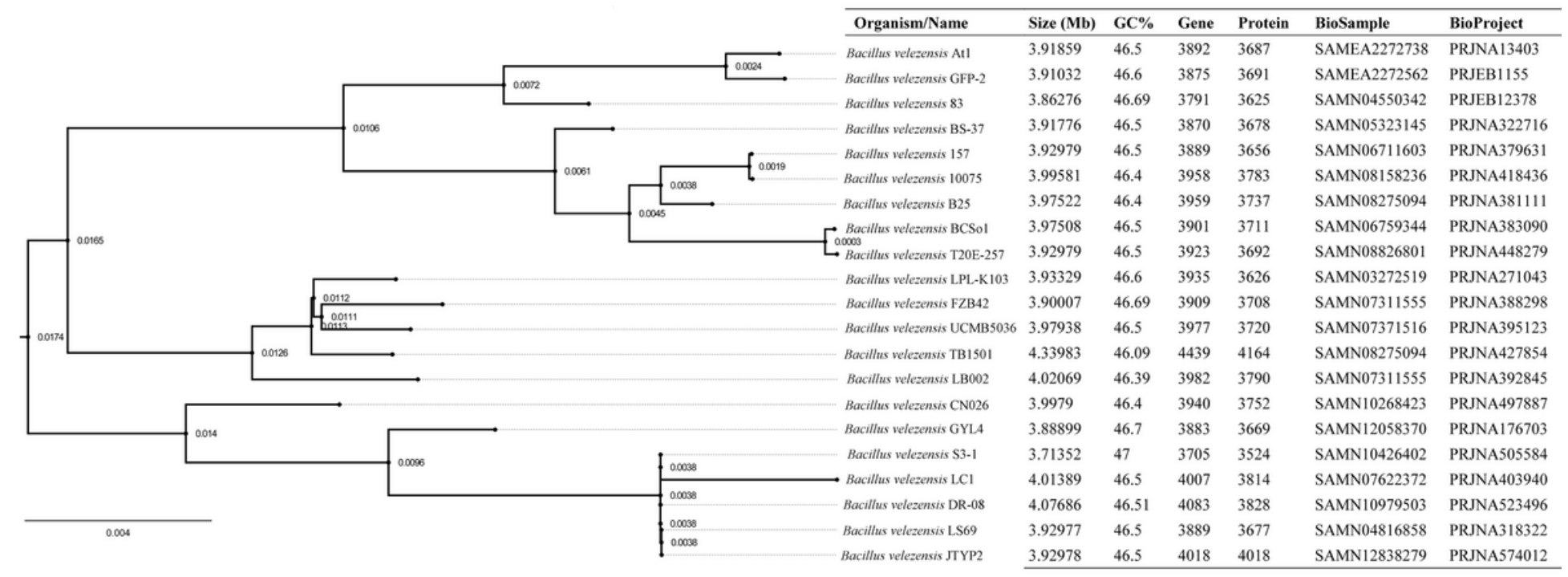

Figure 1

Comparative genomic analysis of the 21 Bacillus velezensis strains and the genome information at the whole genome level. The genome sequences of $B$. velezensis bacteria, $B$. velezensis 10075, B. velezensis 157, B. velezensis FZB42, B. velezensis 83, B. velezensis UCMB5036, B. velezensis LB002, B. velezensis S3-1, B. velezensis At1, B. velezensis BCSo1, B. velezensis JTYP2, B. velezensis BS-37, B. velezensis CN026, B. velezensis B25, B. velezensis DR-08, B. velezensis LPL-K103, B. velezensis GFP-2, B. velezensis T20E-257, B. velezensis GYL4, B. velezensis TB1501, and B. velezensis LS69 were retrieved from the National Centre for Biotechnology Information (NCBl; https://www.ncbi.nlm.nih.gov/). More detailed information is shown in Table S1. A maximum-likelihood phylogenetic tree with 1000 bootstrap replicates was constructed for the concatenated blocks of the aligned sequence using RAxML version 7.2.8 (24) and was visualised using FigTree version 1.3.1 (http://tree.bio.ed.ac.uk/software/fifigtree/).
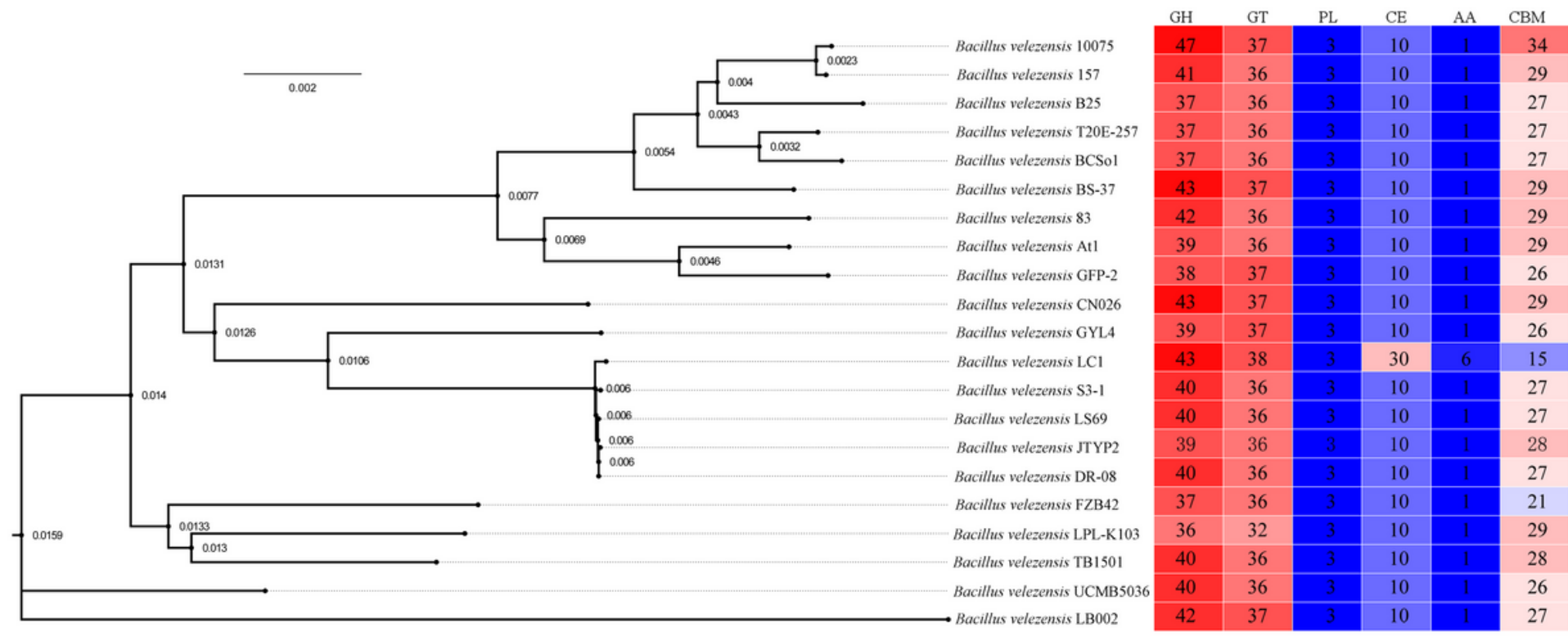

Figure 2 
Comparative CAZyomic analysis of the 21 Bacillus velezensis strains and the amounts of GH, GT, AA, CE, $\mathrm{PL}$ and $\mathrm{CBM}$ at the whole genome level. GH, glycoside hydrolase; $\mathrm{CE}$, carbohydrate esterase; $\mathrm{AA}$, auxiliary activity; PL, polysaccharide lyase;GT, glycosyl transferase; CBM, carbohydrate-binding module; CAZyme, carbohydrate-active enzyme. A maximum-likelihood phylogenetic tree with 1000 bootstrap replicates was constructed for the concatenated blocks of the aligned sequence using RAxML version 7.2.8 (24) and visualised using FigTree version 1.3.1 (http://tree.bio.ed.ac.uk/software/fifigtree/).
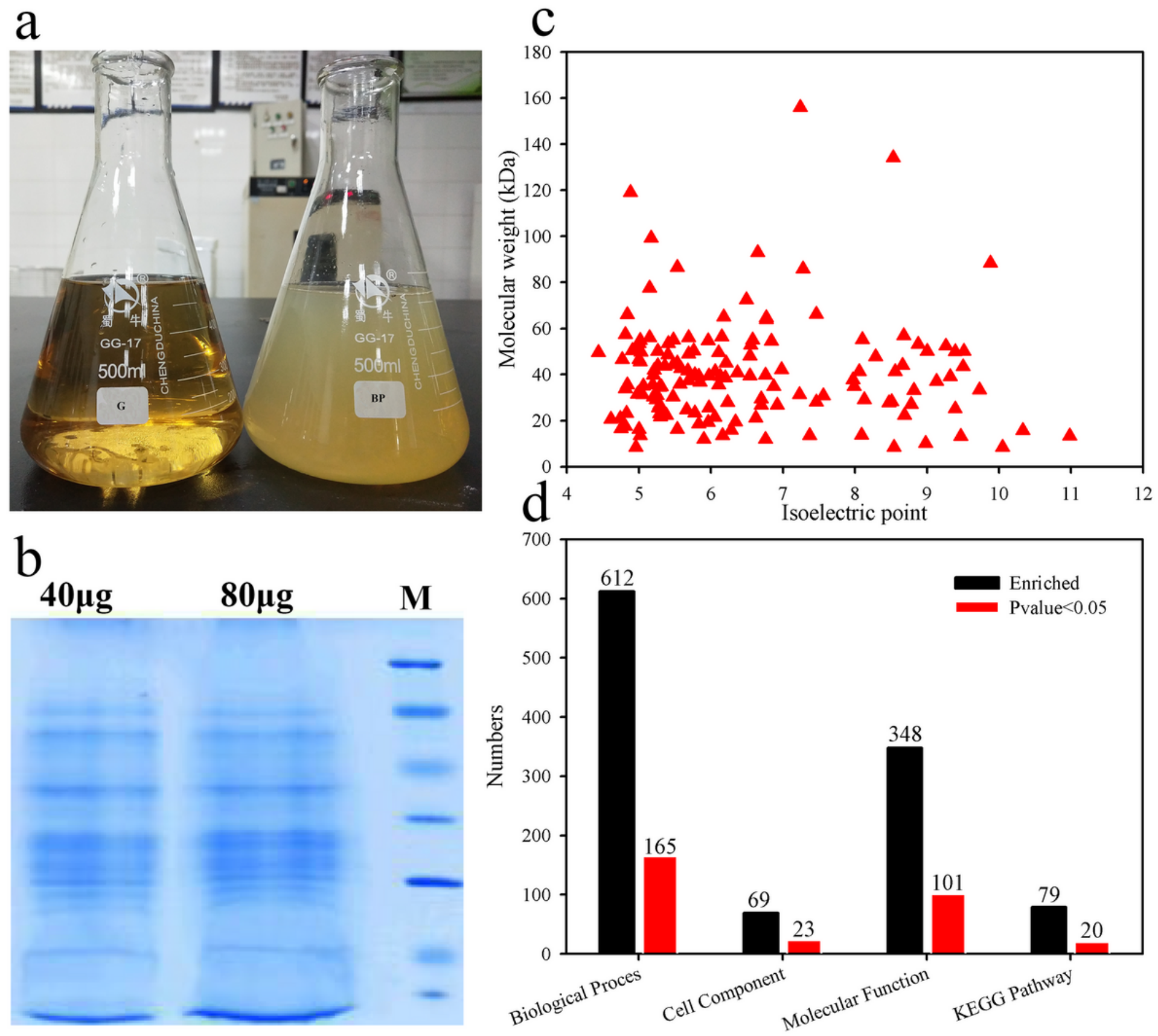

Figure 3

Secretome identification of B. velezensis LC1 in the presence of bamboo powder substrate. a Protein extraction by trichloroacetic acid (TCA). G, glucose substrate, BP, bamboo powder substrate. b 1D-PAGE of proteomes of $\mathrm{B}$. velezensis LC1 grown on bamboo powder-containing medium. c Molecular weight and 
isoelectric focussing of identified proteins. Both the molecular weight and isoelectric point were theoretically obtained using Proteome Discoverer v.1.3 beta (Thermo Scientific) during protein identification. $d$ Functional annotation of identified proteins in the B. velezensis LC1 secretome by LC$\mathrm{MS} / \mathrm{MS}$.
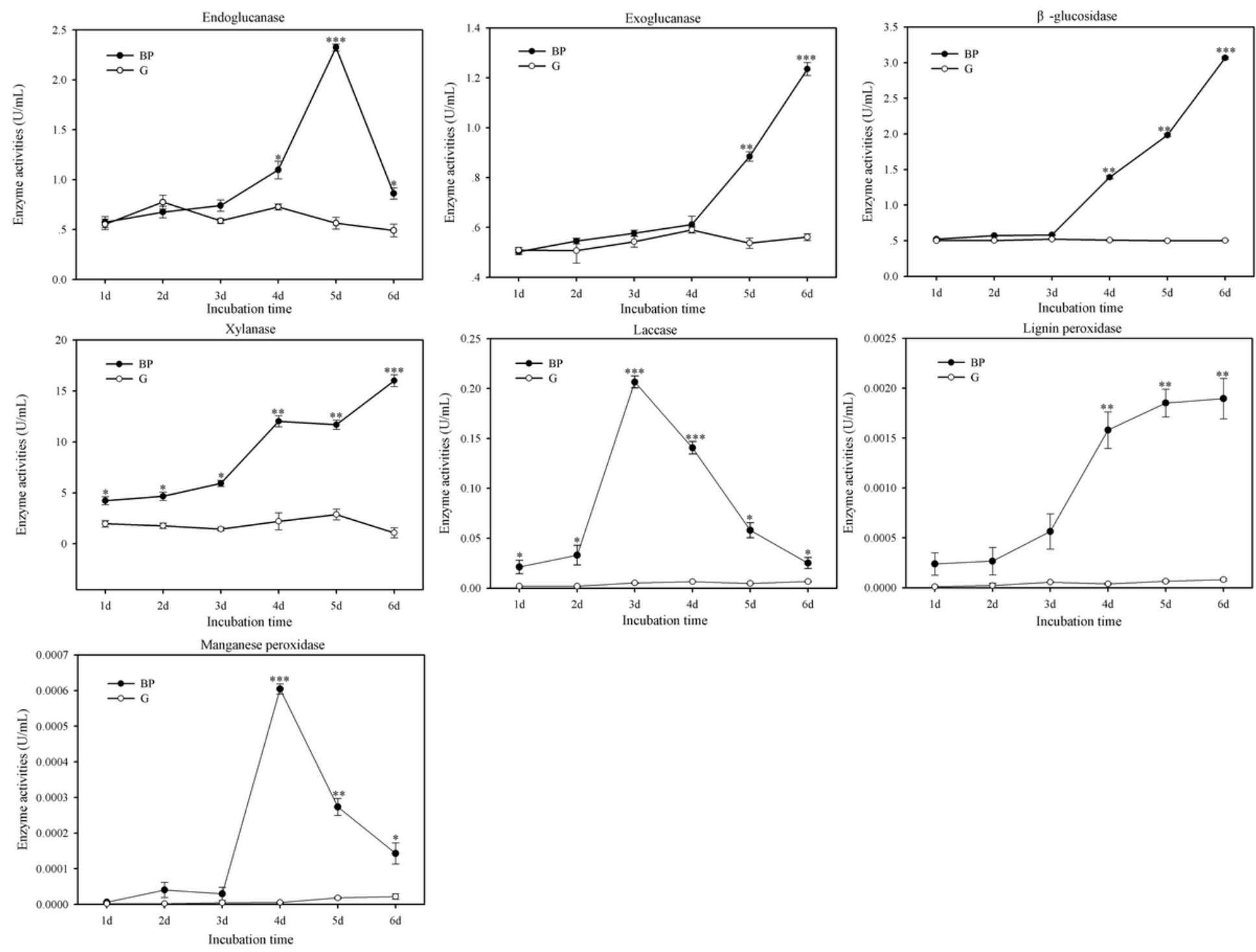

Figure 4

Lignocellulolase activities of B. velezensis LC1. The activities of endoglucanase, $\beta$-glucosidase, exoglucanase, xylanase, lignin peroxidase, laccase, and manganese peroxidase are listed in $a-g$, respectively. G, glucose substrate, $\mathrm{BP}$, bamboo powder substrate. Data are presented as the means and standard deviations of five experiments. Statistical significance: ${ }^{P}<0.05, * \star P<0.01, * \star \star P<0.001$. 

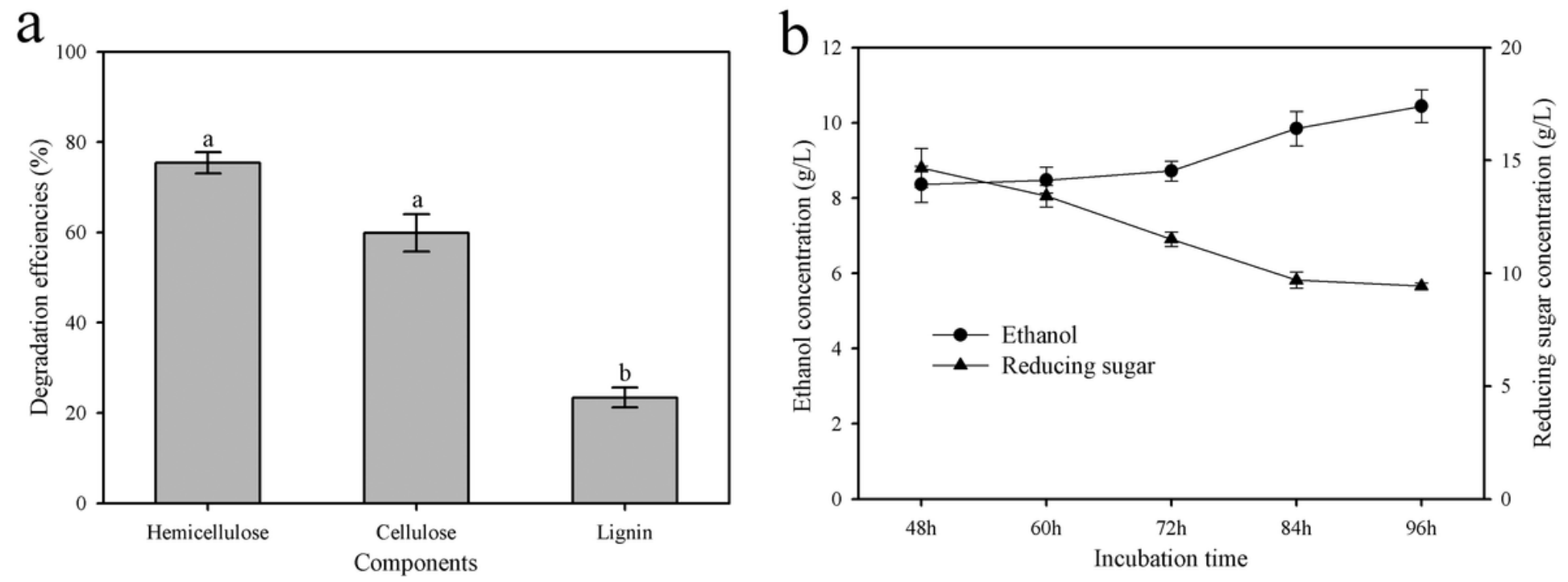

Figure 5

Lignocellulose-degrading efficiencies and fermentation performance of bamboo powder by $\mathrm{B}$. velezensis LC1. a Lignocellulose degradation efficiencies. $b$ Ethanol production and reducing sugar concentrations at $48,60,72,84$, and $96 \mathrm{~h}$. The different letters indicate a significant difference in degradation efficiencies of different components at a $p$ value of $0.05(n=3)$.

\section{Supplementary Files}

This is a list of supplementary files associated with this preprint. Click to download.

- FigureS2.png

- FigureS1.png 